\title{
O corpo em cena: reflexões para a educação escolar
}

\section{The body on stage: reflections for school education}

\section{El cuerpo en escena: reflexiones para la educación escolar}

(D) José Carlos dos Santos
Universidade Federal do Triângulo Mineiro, Uberaba, Minas Gerais, Brasil e-mail: jcprofedf@gmail.com

(iD) Wagner Wey Moreira

Universidade Federal do Triângulo Mineiro, Uberaba, Minas Gerais, Brasil e-mail:weymoreira@uol.com.br

Resumo: Este artigo tem como objetivo refletir sobre o corpo no cenário da educação escolar. Amparado em uma abordagem qualitativa, de cunho bibliográfico, a primeira seção aborda sobre como o corpo tem sido percebido no ambiente escolar. A segunda seção ressalta como ele tem sido sujeito alvo de amplas discussões no Primeiro Ciclo do Ensino Fundamental, destacando o olhar para a corporeidade criança, que adentra na escola cada vez mais cedo. As considerações finais propiciam refletir que, se direcionarmos nosso olhar para a corporeidade na escola, perceberemos que os processos educativos continuam numa perspectiva de querer educar os corpos para serem ágeis, fortes e inteligentes, esquecendo de olhar o ser humano como um sujeito de corpo inteiro.

Palavras-chave: Corporeidade. Educação. Escola.

Abstract: This essay aims to reflect on the body in the school education scenario of the 21 st century. Supported by a qualitative, bibliographic approach, the first section "the body at school" addresses how the body has been perceived in the school environment. The second section 
highlights how it has been the subject of extensive discussion in the First Cycle of Primary Education, highlighting the look at the child's body entering school earlier and earlier. The final considerations allow us to reflect that if we direct our gaze towards corporeality in school, we will realize that the educational processes continue in a perspective of wanting to educate the bodies to be agile, strong and intelligent, forgetting to look at the ordinary human being subject of the whole body.

Keywords: Corporeity. Education. School.

Resumen: Este ensayo tiene como objetivo reflexionar sobre el cuerpo en el escenario de la educación escolar del siglo XXI. Con el apoyo de un enfoque cualitativo y bibliográfico, la primera sección, "el cuerpo en la escuela", aborda la forma en que el cuerpo ha sido percibido en el entorno escolar. En la segunda sección se destaca cómo ha sido objeto de un amplio debate en el Primer Ciclo de la Enseñanza Primaria, destacando la mirada al cuerpo del niño que entra en la escuela cada vez más temprano. Las consideraciones finales nos permiten reflexionar que si dirigimos nuestra mirada hacia la corporeidad en la escuela, nos daremos cuenta de que los procesos educativos continúan en una perspectiva de querer educar los cuerpos para que sean ágiles, fuertes e inteligentes, olvidando mirar al ser humano ordinario sujeto de todo el cuerpo.

Palabras-clave: Corporeidad. Educación. Escuela

Submetido em: 14-07-2019

Aceito em: 23-06-2020 


\section{Introdução}

Ao longo das últimas décadas, o corpo tem sido sujeito alvo de amplas discussões em muitos espaços, sob diferentes aspectos, contextos, práticas e significados (MOREIRA et al., 2006; GALLO, 2006; GAIO; PORTO, 2010; GALLO; ZEPPINI, 2016). Da mesma forma, ele vem sendo evidenciado no campo da educação (BEZERRA; MOREIRA, 2013). Com as mudanças ocorridas na sociedade contemporânea, o corpo retorna à cena como protagonista de análise, especialmente no campo da educação escolar.

Por muito tempo, o nosso modelo de educação escolar esteve pautado sob o alicerce de três aspectos: a visão do homem como máquina, o dualismo corpo-mente e o método racionalista (BARBOSA, 1995; NÓBREGA, 2010; NISTA-PICCOLO; MOREIRA, 2012). Esses aspectos influenciaram a forma de tratar o corpo nos processos educativos na escola, desconsiderando, por muitas vezes, as experiências humanas. Por conta disso, foram priorizadas a reprodução e a fragmentação do conhecimento na mesma proporção que dicotomizaram o fenômeno corpo. Os reflexos dessa influência foram tão fortes que os processos pedagógicos presentes no ambiente escolar foram induzidos a continuar numa proposta de prática reprodutora e de transmissão passiva do conteúdo, considerando a cabeça como ponto central de aprendizado dos alunos (BEHRENS, 2013).

Tradicionalmente, a educação escolar tem privilegiado, principalmente, os aspectos instrutivos e intelectuais. Como consequência disso, muitos alunos vão à escola somente para aprender, de maneira fragmentada e descontextualizada, os conteúdos historicamente produzidos pelo homem (PÁTARO, 2013).

Como a educação escolar está repleta de desafios, conflitos e incertezas, faz-se necessário o reconhecimento de uma visão mais complexa sobre esse fenômeno a partir do corpo. Talvez, uma das formas seja pelo distanciamento desse modelo reducionista, através da busca pelo acolhimento da corporeidade. Prevalecendo, as- 
sim, a dimensão humana e a ética do cuidado com o outro, lutando contra a desumanização, intolerância e rejeição.

Diante disso, surgem indagações que norteiam o desenvolvimento desta investigação: qual o cenário reflexivo acerca do corpo na educação escolar? De que forma o corpo tem sido visto na escola? Além disso, como o corpo tem sido acolhido no Primeiro Ciclo do Ensino Fundamental?

Buscando possíveis respostas a essas indagações, este artigo pautou-se nos pressupostos da abordagem qualitativa, de cunho bibliográfico, apresentando dois temas que se interpenetram: Corpo e Educação. Nele, procuramos articular os argumentos teóricos, enriquecidos por pressupostos teóricos com vistas à valorização da "corporeidade" no processo da educativo da Educação Escolar. Cabe salientar que a pesquisa bibliográfica, segundo Gil (2010), trata-se daquela que é desenvolvida a partir de um material já elaborado, podendo ser constituído por artigos científicos, livros, teses e dissertações.

Sendo assim, a primeira seção deste artigo traz uma análise do "Corpo na escola", apontando como ele é tratado no ambiente escolar, intentando reflexões sobre a disciplinarização corpórea, docilização do movimento e o adestramento enraizado nas práticas educativas presentes na educação. E a segunda seção se propõe a discutir sobre o corpo no Primeiro Ciclo do Ensino Fundamental $(\mathrm{EFI})$, tecendo pontos acerca do corpo e corporeidade no processo de ensino e aprendizagem.

Nesse sentido, o presente estudo tem como objetivo refletir sobre o corpo no cenário da educação escolar.

\section{Ato I - O corpo na escola}

Falar sobre o corpo é adentrar num universo complexo e requer a necessidade de olharmos para o ser humano e sua essência. No campo escolar, ele tem gerado inúmeras discussões em torno da preocupação dos professores com a disciplina corporal 
dos alunos, além da supremacia dos conteúdos mais voltados para os aspectos cognitivos, distanciando o corpo cada vez mais do processo educativo e das experiências corporais. Talvez, uma das razões seja porque a liberdade expressiva do corpo dos estudantes ainda assusta os professores.

Tocantins (2012, p. 50) aponta que "o corpo na escola continua a ser entendido da mesma forma que na sociedade, um objeto a serviço da mente que precisa ser educado para servir de força produtiva". A afirmação da autora demonstra a influência da racionalidade do paradigma cartesiano ao tratar o corpo no ambiente escolar. Inforsato (2006, p. 101) revela que "se o racionalismo cartesiano, um dos pilares da modernidade, acarretou a supremacia da cabeça, lugar do cérebro, sobre os outros órgãos, um dos agentes dessa ideologia foi claramente a escola."

Moreira (2005) aponta que a escola trata o ser humano a partir de uma visão dual, fragmentando o aluno em corpo e mente na sala de aula, reconhecendo e interpretando as ações corporais como atos de indisciplina. Valeirão (2012) destaca que as instituições de ensino promovem e exercem, a partir das práticas pedagógicas dos professores, a ordem e o poder disciplinar, agindo assim como um dispositivo controlador, definindo o que pode ser dito, feito, pensando e vivenciado no ambiente escolar.

Assim, é importante salientar que não é apenas mudando as práticas pedagógicas dos professores que teremos transformações imediatas quanto ao poder disciplinador exercido sobre o corpo no ambiente escolar. Kohan (2008, p. 18) evidencia que até “[...] podemos sentar os alunos em círculo, em confortáveis travesseiros, com roupas coloridas e numa sala bem arrumada para controlar e disciplinar mais sofisticadamente seus corpos [...]".

Moreira (1995, p. 28) defende uma educação de corpo inteiro ao afirmar que "a educação se processa no corpo todo e não apenas na cabeça dos alunos". Probst e Kraemer (2012, p. 508) sinalizam que "para compreender qual o lugar do corpo na escola não basta localizá-lo e simplesmente "depositá-lo" na escola". 
Toda educação perpassa pelo corpo, porém há resquícios de práticas educativas que evidenciam a supervalorização dos aspectos intelectuais, colocando-o apenas como um acessório destinado a manifestar-se em razão das capacidades mentais no ambiente escolar (ALMEIDA; AZEVEDO-MARTINS; NUNES, 2013). Partindo dessa premissa, Foucault (2014) expõe que essas ações podem ser tidas como fontes para a manipulação, modelação, adestramento e obediência do ser humano, surgindo a partir daí uma noção de docilidade (corpos dóceis), apontando essas estratégias como possíveis mecanismos para exercer o poder sobre o corpo.

Strazzacappa (2001) considera tais estratégias como algo inadmissível, pois é através das ações do corpo que os processos de aprendizagem e de comunicação com o outro se estabelecem, possibilitando sentir o mundo e ser sentido por aqueles que estão à sua volta. Nóbrega $(2005$, p. 610) revela que "[...] os cuidados com o corpo podem e devem ser tematizados nas diferentes práticas educativas propostas nos currículos e viabilizados por diferentes disciplinas", ou seja, torna-se cada vez mais necessário abordar sobre o corpo na escola.

Nessa direção, Tiriba (2008, p. 10) nos faz refletir ao dizer que:

A escola precisa recuperar a liberdade de movimentos que a vida na cidade grande e seu respectivo modelo de funcionamento escolar restringiram, impedindo as mais simples e fundamentais manifestações como correr, pular, saltar, etc.

O espaço escolar não é um lugar multiplicador de elementos que buscam formas de reduzir as ações corporais dos alunos, pelo contrário, o corpo precisa existir na sala de aula, precisa existir na escola. Dessa forma, corroboramos o pensamento de Probst e Kraemer (2012) quando dizem que os professores, através das práticas pedagógicas, precisam conceber um ambiente escolar democrático, no qual o aluno possa exercer a liberdade e expressividade corporal do seu ser, sejam elas através da fala, do olhar, do andar. 
Para Freire e Dantas (2012, p. 149), a instituição escolar tem uma grande missão a ser realizada, sendo:

[...] fundamental que se abra um espaço para a construção de representações do corpo e dos valores que a ele se atribui. É importante perceber esse espaço como lugar privilegiado para refletir sobre a formação dos sujeitos, desmistificando estigmas, estereótipos, valores e atitudes, buscando assim, humanizar a prática pedagógica.

O corpo é condição existencial na qual sua linguagem não pode ser silenciada no ato educativo, pois, enquanto fenômeno, ele está presente na educação (NÓBREGA, 2010; SANTIN, 2003). Se partirmos do pressuposto de que a escola é o espaço onde acontecem as mais variadas experiências humanas, parece-nos que é cada vez mais importante repensarmos sobre corporeidade. Afinal, um ambiente escolar não pode estar apenas ligado ao campo dos conhecimentos cognitivos e intelectuais, mas também nas múltiplas dimensões que possam fazer o ser humano refletir sobre valores. Portanto, aqui, ancoramo-nos em Rios e Moreira (2015) ao julgarem necessário que se estabeleçam propostas pedagógicas que sejam capazes de pensar no aluno como um todo.

Sabemos que contextualizar esse modelo de educação baseado na aprendizagem significativa através do corpo dos estudantes é uma missão desafiadora para os professores. Para que isso ocorra, os educadores precisam ter a certeza de que estão seguindo por caminhos até então desconhecidos, que exigirão deles segurança e determinação para propor novas formas de refletir o sobre o corpo no ambiente escolar (SOBREIRA; NISTA-PICCOLLO; MOREIRA, 2016). Um dos caminhos possíveis para repensar o trato do corpo na escola é através da corporeidade, como uma possibilidade de ato educativo.

Sendo assim, buscamos refletir no que disseram Moreira et al. (2006, p. 42): 
A dimensão de uma educação para a existência humana, via corporeidade, requer ver-se a si próprio para melhor ver fora de si, pois aqui está a linha de ruptura possível entre o pensamento mutilado/ mutilador e o pensamento complexo. O "eu" é, ao mesmo tempo, expulso (da reflexão) e arrogante (heliocêntrico) no pensamento mutilado/mutilador. Já o conhecimento complexo exige que nos situemos na situação, nos compreendamos na compreensão e nos conheçamos aos conhecermos. Daí a difícil arte de pensar, mesmo porque não há receitas para pensar bem. Pensar é um problema vital.

Essa condição nos proporciona a visão de uma educação muito mais ampla, pois considera o corpo como sujeito que constrói sua história e cultura, ao mesmo tempo que busca aprender mais sobre os outros que estão à sua volta, sendo imprescindível considerar a existência humana como base para o aprendizado escolar. Por essa razão, os alunos precisam de um modelo de educação que respeite a complexidade de seu corpo (NISTA-PICCOLO; MOREIRA, 2012).

Uma educação escolar sob a ótica da corporeidade poderá possibilitar aos professores transformarem suas práticas pedagógicas em projetos de humanização através do corpo do aluno na escola. Desse modo, eles poderão promover um espaço escolar que reconheça a participação de corpo inteiro do aluno, destacando-o como agente ativo na construção da sua corporeidade, dando autonomia de movimentos corporais e a chance de (re)significar o corpo no processo de ensino e aprendizagem (RIOS; MOREIRA, 2016; FREIRE; DANTAS, 2012).

Sobreira, Nista-Piccolo e Moreira (2016, p. 72) destacam que:

Educar tendo como princípio a corporeidade, significa acreditar na explicitação das relações homem/mundo/sociedade/cultura. Para isto há que se alterar valores, rechaçar modismos, explicitar a importância da existência, dedicar esforço na busca do ser mais, buscar transcendência, caminhar na direção do conhecimento contextualizado que englobe outros e mundo. 
Oliveira (2010) revela que valorizar a corporeidade no âmbito da educação poderá possibilitar caminhos para superar o modelo enraizado no pensamento educacional. Para a autora, as práticas educativas instituídas pelos professores necessitam incluir a corporeidade como base de formação humana. Nesse contexto, podemos tentar pensar num modelo de educação que direcione nossos alunos através de seus corpos para um caminho que destaque a existência humana.

Freire e Dantas (2012) revelam que proporcionar estudos e discussões acerca do corpo no âmbito da educação escolar pode proporcionar reflexões e apontar outros significados para o aluno e para o ato educativo, provocando, assim, transformações no que tange às mudanças de comportamentos, valores e atitudes. Dessa forma, entendemos o porquê da importância de a corporeidade ser inserida nas práticas pedagógicas dos professores.

Parece distante da nossa realidade o trato com o corpo via corporeidade no ambiente escolar, porém compreender o fenômeno corpo na perspectiva da corporeidade é demonstrar sua singularidade, sua essência. Não há mais o porquê de negarmos a corporeidade na escola. É preciso trilhar por esse caminho sugerido por Porpino (2006, p. 68) ao dizer que "cabe-nos viver o corpo em sua fenomenologia, voltarmos a ele nos voltando a nós mesmos, às nossas mais sutis experiências". Devemos viver o corpo e todas as suas manifestações no ambiente escolar.

Será um desafio para os educadores. Mas, sem dúvida, será também primordial pensar sobre a corporeidade e o lugar do corpo na escola, principalmente nas práticas educativas. Talvez, a partir desse ponto, poderemos pensar numa escola mais humana e preocupada não apenas com os saberes, estratégias mecânicas e silenciadoras de corpos. 


\section{Ato 2 - O corpo no primeiro ciclo do Ensino Fundamental}

Iniciamos esta seção com algumas questões reflexivas, a nosso ver, que imperam neste trabalho: qual o sentido de abordarmos, nesse momento, sobre o corpo no Ensino Fundamental? O que significa, afinal, falar do corpo no Primeiro Ciclo do Ensino Fundamental (EFI)?

Compondo esse cenário, temos o ser criança adentrando cada vez mais cedo no ambiente escolar e, por ser criança, apresenta a necessidade de realizar atividades que envolvam o movimento corporal no processo de ensino e aprendizagem.

Todavia, Sá (2015, p. 188) propõe-nos uma reflexão quando diz:

[...] há na sala de aula uma contenção das crianças, não deixando que elas se desloquem ou se manifestem, reprimindo a vontade da criança, criando um desconforto. [...] o movimento corporal funciona como quebra de rotina de sala de aula, como momento de descontração.

Garanhani (2008, p. 137) evidencia que quando a criança adentra a escola ela possui significados, pois:

[...] independentemente da idade em que se encontra, a criança traz consigo saberes sobre os movimentos que realiza com seu corpo, apropriados e construídos nos diferentes espaços e relações em que vive. Desse modo, a escola poderá sistematizar e ampliar o conhecimento da criança sobre o seu movimentar.

Nesse percurso, o papel do professor é muito importante, principalmente no que tange conhecer a criança inserida nesse espaço novo chamado escola. Lima (2005) revela que o professor só poderá exercer plenamente o seu papel de educador quando 
O corpo em cena: reflexões para a educação escolar José Carlos dos Santos · Wagner Wey Moreira

reconhecer as potencialidades e as manifestações do ser criança. Nesse ciclo, o professor poderá utilizar-se da ferramenta da ludicidade e do movimento humano como eixos estruturantes para a formação da criança (SARMENTO, 2004).

Fonseca (2008) destaca que a criança, nessa fase, pode obter um maior domínio corporal, podendo adquirir consciência de si a partir das relações que são estabelecidas na escola. Porém, Pedrosa e Mello (2012) apontam que a criança, ao adentrar no primeiro ciclo do Ensino Fundamental, utiliza bem menos o brincar e o movimentar-se, pois essas atividades podem não se encaixar muito bem no espaço na qual elas vão para buscar o saber.

Barcelos, Santos e Neto (2015, p. 87) evidenciam que, no Ensino Fundamental, a centralidade está direcionada para "[...] apropriação da escrita, leitura, cálculo e na incorporação das normas e condutas produzindo uma dicotomização entre brincar e aprender, como se fossem ações antagonistas no trabalho pedagógico com as crianças [...]".

Parece que o primeiro ciclo do EFI está destinado, em sua essência, a sanar os problemas direcionados à escrita, às leituras e à compreensão das fórmulas matemáticas. Como reflexo do modelo proposto no EFI, Motta (2011, p. 167) diagnosticou, no estudo intitulado De crianças a alunos: transformações sociais na passagem da educação infantil para o ensino fundamental, realizado em três escolas públicas que ofertam o primeiro ano do Ensino Fundamental, que:

\begin{abstract}
A expressão do corpo revelava uma aprendizagem; a sala de aula, no ensino fundamental, era um espaço de movimentos mais contidos, as vozes reguladas num volume mais baixo. Os movimentos não autorizados deveriam ser feitos de maneira rápida e sutil, preferencialmente quando a professora não estivesse atenta. Percebia-se aqui uma sujeição dos corpos infantis à lógica das culturas escolares, que conformam um tipo de subjetividade bem específica: a do aluno.
\end{abstract}


Os achados de Motta (2011) direcionam-se para o que afirma Machado (2013, p. 39):

\begin{abstract}
As crianças desde cedo são orientadas com relação à forma de se comportarem: sentar, comer à mesa, brincar sem machucar, andar, enfim são conduzidas por um adulto a descobrir formas para serem aceitas nos mais diferentes grupos e na escola essas ideias são fomentadas com mais vigor. As regras são impostas em função do que se considera ideal enquanto formação efetiva da criança. Nesses ambientes, as crianças apenas escutam e obedecem aos adultos, que em muitos casos, transmitem conhecimentos oralmente com tons ameaçadores ou de maneira incompreensível.
\end{abstract}

Freire (2005) revela que o corpo da criança na escola é submetido ao silêncio, ao cumprimento de regras. Tudo isso em prol do não movimento corporal e, talvez, para impedir que a criança tenha voz. Pena, Bogéa e Borges (2008) apontam que a rotina da escola gera no corpo da criança padrões de comportamento e automatismo nas relações na sala de aula, além de uma possível acomodação de corpos. Para as autoras, não há lugar para o surgimento de crianças livres e expressivas.

Corroboramos o pensamento de Probst e Kraemer (2012) ao afirmarem que não se pode mais apenas pensar no corpo da criança inserida no EFI como um corpo disposto e à mercê do recebimento de uma ação pedagógica capaz de possibilitar o movimento de forma espontânea. Nesse ponto, nos debruçamos no imaginário de que o ser criança não tem uma vontade própria e, tampouco, preenchida por desejos e nem mesmo são criadoras de si e do mundo.

Todas as ações e intenções passam pelo corpo e é somente sendo corpo que as crianças poderão se relacionar com o mundo-vida e com as atividades educativas desenvolvidas em sala de aula. Porém, há muito a se fazer nas séries iniciais do EFI. Uma delas é oportunizar o ser criança a aprender através da sua condi- 
ção de existência corporal, ou seja, brincando, jogando e não apenas sendo enclausurada em sua sala de aula de forma estática e inexpressiva.

Para nós, torna-se cada vez mais importante superarmos as práticas educativas que vislumbrem o engessamento dos corpos das crianças no EFI por meio da atuação de alguns professores que não valorizam a aprendizagem de corpo inteiro, desconsiderando a formação humana como elemento essencial na educação. Assim, ratificamos as conclusões de Machado (2013) quando diz que o corpo da criança precisa e merece ser respeitado no ambiente escolar e carece de uma atenção maior dos professores no ato do processo educativo via ações corporais.

A corporeidade criança carece, em sua essência, de ser preparada sob a ótica de ser uma totalidade. Portanto, é preciso que os educadores estejam atentos ao "aprendermos a ser". Morin (2011) nos propõe refletir quando aponta que todo ser humano deve ser visto e preparado para o todo (espírito e corpo, ética e espiritualidade, sentido estético e responsabilidade pessoal, inteligência e sensibilidade). Esse pensamento nos faz repensar, e até mesmo sugere,que possa haver (re) elaborações de práticas educativas mais sensíveis e humanas para com os alunos.

Santos e Moreira (2020) evidenciaram que estudos centrados na corporeidade criança e em suas ações corporais, como também no seu jeito de ser e estar no mundo, como ponto central de discussão ainda são recentes. Gonçalves (2013), por sua vez, retrata que parece comum no modelo de educação vigente adotar, desde cedo, uma proposta de submeter o corpo do aluno a regras autorreguladoras do comportamento humano e, principalmente, das suas ações no ambiente escolar que, de alguma forma, representa um sacrifício direcionado ao corpo da criança.

Há pesquisadores/autores preocupados com a corporeidade criança nas séries iniciais do EFl, como é o caso de Magrin, Cintra e Moreira (2016), na investigação $O$ corpo e o professor de tempo integral. Os autores diagnosticaram que, do total de quatro profes- 
sores, apenas um desses sujeitos trabalhava com uma proposta de ação educativa numa perspectiva mais unitária do ser, apresentando, assim, reflexões de possíveis estratégias de trabalho dos conteúdos abordados, considerando aquilo que Santos (2019) evidenciou como corporeidade criança entrelaçada como sujeito fenomenológico no processo de ensino-aprendizagem.

Há, no entanto, muito preconceito contra o movimento do corpo na sala de aula por parte dos professores, que, por serem adultos, acabam controlando suas ações, resultando, assim, em repressão aos alunos mais agitados corporalmente no ambiente escolar (PROBST; KRAEMER, 2012).

Isso acontece porque ainda há uma concepção de que criança educada e comportada é aquela que não se movimenta, não se expressa corporalmente. Talvez, um dos possíveis motivos seja porque os professores do EFI tenham em mente que a escola é o espaço preparador para o cidadão do futuro e, como tal, carece de pessoas obedientes, silenciosas. Para Skliar (2012), a escola parece ser o lugar aonde nossas crianças vão para se tornarem adultas e abandonarem a sua condição existencial de ser corporeidade aprendente.

Siqueira (2014) revela que o corpo e o pensamento do aluno não são valorizados no processo de aprendizagem dos conteúdos, demonstrando, assim, que o movimento corporal não é bem visto em muitas metodologias educacionais. Por isso, temos uma supremacia das experiências de ordem cognitivas, em razão das experiências motoras e afetivas no ambiente escolar e, consequentemente, nas práticas educativas dos professores.

Concordamos com Skliar (2012) ao dizer que os professores poderiam afastar-se da supremacia do ato de "interromper" a criança e o seu movimento corporal, além de adotar, quando possível, atitudes que possam direcionar para o exercício da escuta, do olhar e do respeitar a criança como corpo sujeito, buscando, principalmente, aprender com o que elas têm a nos ensinar. Desse modo, poderíamos facilmente abandonar aquilo que foi diagnos- 
ticado por Beber (2014), quando este percebeu, em sua investigação, que as práticas pedagógicas dos professores submetiam a corporeidade criança a manter-se silenciosa, quieta, contendo, assim, o ser corpóreo que são, deixando claro o poder exercido pelos professores sobre o corpo/corporeidade da criança.

Fonseca (2009), ao investigar se as crianças de duas turmas de uma escola pública, na cidade Juiz de Fora - MG, aceitavam ou resistiam às propostas educativas embasadas na docilização, disciplinarização e condução do modo de ser no espaço escolar, acabou evidenciando que as professoras, através de suas práticas pedagógicas, criavam modos para que as crianças pudessem ter a liberdade e criatividade durante as aulas, permitindo, assim, que elas escapassem da "disciplinarização do corpo infantil".

A partir do exemplo citado, é perceptível que nós professores podemos ir na contramão do poder disciplinador do corpo criança no primeiro ciclo do EFI. Uma possibilidade é reconhecer que a criança, nessa etapa dos estudos, precisa passar pela fase da vivência e experiência corporal, ou seja, precisa vivenciar o correr, o brincar, o dançar e conhecer-se enquanto corporeidade aprendente (SANTOS, 2019).

Alexandrino, Lima e Ferreira (2014, p. 90) são categóricos ao afirmar que "a criança precisa ter suas próprias experiências e não ser sempre guiada pelos adultos, pois é pela sua prática pessoal, pela sua exploração que se ajusta, domina, descobre e compreende o meio em que vive."

É preciso que nós professores superemos as ideias platônicas que foram incorporadas no ambiente escolar, em especial aquelas que consideram o corpo da criança como um objeto que pode ser facilmente mensurável, manipulado e controlado.

É notório que há inúmeros professores que não deixam os seus alunos expressarem o que sentem e nem mesmo circularem pela sala de aula. Sabemos que existem docentes que assumem tal postura e, não obstante, assumem posturas pedagógicas que reafirmam ser um fator complicador o movimento corporal das 
crianças no ambiente escolar, principalmente no primeiro ciclo, pois trata-se de alunos mais jovens e enérgicos.

Concordamos com Fonseca (2009) ao dizer que a escola, por meio das práticas pedagógicas dos professores, pode buscar sensibilizar as crianças propondo dinâmicas, jogos e outras atividades, nas quais elas possam estabelecer contato, usar a criatividade, pensar e, até mesmo, instigá-las a novas descobertas e potencialidades através do corpo que são. Da mesma forma, vislumbramos o desejo de Rios e Moreira (2015, p. 52) ao dizerem que "necessitamos pensar em uma escola, uma sala de aula em que nossos alunos sejam vistos de forma integral, indissociável, como as experiências vivenciais do corpo em consonância com a mente."

Rios e Moreira (2015) parecem descrever nossos pensamentos quando apontam a necessidade de termos uma prática pedagógica que seja baseada na ludicidade e no campo criativo, de modo que possa valorizar as relações estabelecidas via corpo, possibilitando aos alunos demonstrarem suas emoções, prazeres, sentimentos e, até mesmo, suas dificuldades. Para tal, Rios e Moreira (2016, p. 234) dizem:

\footnotetext{
"Quando observamos a criança se movimentando, executando suas ações tal separação é impossível de se realizar e não podemos reduzir o corpo durante o processo educativo, porque só conseguimos produzir porque somos corpo em busca de nossa transcendência.
}

Se é impossível destacarmos essa divisão, por que ainda presenciamos práticas educativas de professores no EFI que insistem em padronizar e controlar o corpo das crianças? A partir desse questionamento, recorremos à corporeidade como uma tentativa de chamar a atenção dos professores que atuam nessa etapa da Educação Básica (EB).

Entendemos ser essencial interpretar o sentido de corporeidade através do que propõe Moreira (2003, p. 148): 
[...] Corporeidade é voltar os sentidos para sentir a vida em: olhar o belo e respeitar o não tão belo; cheirar o odor agradável e batalhar para não haver podridão; escutar palavras de incentivo, carinho, de odes ao encontro, e ao mesmo tempo buscar silenciar, ou pelo menos não gritar, nos momentos de exacerbação da racionalidade e do confronto; tocar tudo com o cuidado e a maneira de como gostaria de ser tocado; saborear temperos bem preparados, discernindo seus componentes sem a preocupação de isolá-los, remetendo essa experiência a outros no sentido de tornar a vida mais saborosa e daí transformar sabor em saber. Corporeidade é buscar transcendência, em todas as formas e possibilidades, quer individualmente quanto coletivamente. Ser mais, é sempre viver a corporeidade, é sempre ir ao encontro do outro, do mundo e de si mesmo. [...]

Nóbrega (2010) afirma que a corporeidade se revela a partir da dinâmica dos processos orgânicos, entrelaçando a história, os afetos, a cultura, permitindo, assim, o surgimento de uma linguagem sensível, conectada ao universo da corporeidade. O fenômeno corpo e as possibilidades do movimento humano passam a sinalizar a existência do sensível, que nos propõe refletir sobre o ser humano e buscar compreender mais o que venha a ser conhecimento.

O corpo é, sem dúvida, o sujeito principal no processo de ensino e aprendizagem. Se estivermos atentos aos sinais da corporeidade criança em todas as dimensões que a compõe, é possível evidenciarmos aprendizagens mais significativas, reverberando prazeres, pois, como já foi dito: é possível aprender brincando.

Temos a consciência de que o fenômeno corporeidade não é a chave para mudar o mundo, nem mesmo para solucionar todos os problemas e dificuldades enfrentados na escola. Por outro lado, ela poderá nos propor reflexões sobre o corpo que está inserido no espaço escolar, assim como poderá nos assegurar que, enquanto sujeitos corpóreos, mantemos nossa relação com o mundo através do corpo que somos (MOREIRA; SIMÕES, 2006). 
Sabemos que compreender o ser criança e sua manifestação corpórea requer de nós sensibilidade e uma percepção para o ser humano além dos estereótipos já existentes. Não é uma tarefa fácil, mas fica aqui nosso desejo para uma educação pautada na sensibilidade e não apenas nas práticas educativas que enclausuram a corporeidade criança, afastando-as cada vez mais do prazer e da liberdade de serem livres no ambiente escolar (SANTOS, 2019).

\section{Considerações finais}

Este estudo buscou propor uma reflexão sobre o corpo no cenário da Educação escolar. E, diante do problema de pesquisa, chegamos à reflexão de que, ao mergulharmos nos debates acerca do protagonismo do corpo no cenário da educação escolar, existe a necessidade de haver mais discussões que sejam pautadas numa visão de educação humanizadora, tendo como premissa o ser humano por inteiro, pois existe um interesse exacerbado que permeia o processo educativo: a preferência pelo conhecimento cognitivo em detrimento das experiências corporais.

Ao voltarmos nosso olhar para a corporeidade no cenário da educação escolar, perceberemos que ainda há fortes indícios de processos educativos enraizados numa perspectiva de querer educar os corpos para serem ágeis, fortes, belos, saudáveis e inteligentes, esquecendo da sensibilidade de olhar o ser humano como um sujeito de corpo inteiro.

Ressaltamos a importância de haver mais estudos e reflexões acerca da corporeidade e do corpo no cenário da escolar, principalmente investigações que busquem evidenciar a expressividade da corporeidade sob a ótica de uma educação fenomenológica. 


\section{Referências}

ALEXANDRINO, D. F. L.; LIMA, C. L.; FERREIRA, M. E. C. A infância perdida: o corpo vivido pede passagem nas séries iniciais do ensino fundamental. Dialogia, São Paulo, n. 19, p. 81-92, jan./jun 2014. Disponível em: http://periodicos.uninove.br/index.php?journal=dialogia\&page=article\&op=view\&path\%5B\%5D=3071\&path\%5B\%5D=2728. Acesso em: 02 de dez. 2018.

ALMEIDA, E. B. de.; MARTINS-AZEVEDO, A. K.; NUNES, V. A. O corpo como espaço de aprendizagem: reflexões a partir das vivências de um grupo de teatro formado por adultos na maturidade. Pro-Posições, Campinas, 24, n. 3, p. 201-217, 2013.

ARAÚJO, A. C. de. Correr, saltar, lançar e dialogar: uma reflexão sobre corpo e aprendizagens nas aulas de educação. 2005. n.p. Dissertação (Mestrado em Educação) - Programa de PósGraduação em Educação, Universidade Federal do Rio Grande do Norte, Natal, 2005.

BARBOSA, M. A. A influência do paradigma cartesiano e emergente na abordagem do processo saúde-doença. Revista da escola de Enfermagem da USP, São Paulo, v. 29, n. 2, p. 133-140, 1995. BARCELOS, M.; SANTOS, W. dos.; NETO FERREIRA, A. Crianças, infância e escolarização: tessituras na transição da educação infantil para o ensino fundamental de nove anos. Motrivivência, Santa Catarina, v. 27, n. 45, p. 84-101, 2015.

BEBER, I. C. R. As experiências do corpo em movimento das crianças pequenas: reflexões para a pedagogia da infância. 2014, 195f. Tese (Doutorado em Educação) - Universidade Federal do Rio Grande do Sul, Faculdade de Educação, Porto Alegre, 2014.

BEHRENS, M. A. O paradigma emergente e a prática pedagógica. 6 ed., Petrópolis: Vozes, 2013. 
BEZERRA, F. L. L.; MOREIRA, W. W. Corpo e educação: o estado da arte sobre o corpo no processo de ensino aprendizagem. Revista Encontro de Pesquisa em Educação Uberaba, Uberaba, v. 1, n.1, p. 61-75, 2013.

FONSECA, A. de C. Disciplinando o corpo de Alice: maravilha e controle na escola contemporânea. 2009. n.p. Dissertação (Mestrado em Educação Física) - Universidade Federal de Juiz de Fora, Minas Gerais, 2009.

FONSECA, V. da. Desenvolvimento psicomotor e aprendizagem. Porto Alegre: ARTMED, 2008.

FOUCAULT, M. Vigiar e punir: história da violência nas prisões. 34 ed. Petrópolis, Rio de Janeiro, 2007.

FREIRE, I. M.; DANTAS, M. H de. A. Educação e corporeidade: um novo olhar sobre o corpo. Holos, Natal, v. 4, n. 28, p. 148-157, 2012.

FREIRE, J. B. Dimensões do Corpo e da Alma. In: DANTAS, Estélio H. M. (Org.) Pensando o corpo e o movimento. 2 ed. Rio de Janeiro, Sharpe, 2005.

GAIO, R.; PORTO, E. A Educação Física e Pedagogia do movimento: possibilidades do corpo em diálogo com as diferenças. In: DE MARCO, A. (Org.). Educação Física: Cultura e Sociedade. Campinas, SP: Papirus, 2010. p. 09-24

GALLO, S. Corpo e Filosofia. In: MOREIRA, W. W.; NISTA-PICCOLO, V; L. (org.). Século XXI: a era do corpo ativo. Campinas, SP: Papirus, 2006. p. 09-31.

GALLO, S.; ZEPPINI, P. S. “O que pode um corpo?": perspectivas filosóficas para a corporeidade. In: MOREIRA, W. W.; NISTAPICCOLO, V.L. (org.). Educação Física e Esportes no século XXI. Campinas, SP, Papirus, 2016. p. 107-132.

GARANHANI, M. C. A educação Física na Educação Infantil: uma proposta em construção. In: FILHO, N. F de A; SCHNEIDER, O (Orgs). Educação física para a educação infantil: conhecimento e especificidade. São Cristóvão, UFS, 2008. p. 123-142. 
GIL, A. C. Como elaborar projetos de pesquisa. São Paulo: Atlas, 2010.

GONÇALVES, A. S. O corpo na educação física escolar: significados e possibilidades de (re) construção. 2013, 192f. Dissertação (mestrado em Educação Física) - Universidade de Brasília, Distrito Federal, 2013.

INFORSATO, E. C. A educação entre o controle e libertação do corpo. In: MOREIRA, W. W (org.). Século XXI: A era do corpo ativo. Campinas, SP: Papirus, 2006. p. 91-108.

KOHAN, W. A escola, a disciplinarização dos corpos e as práticas pedagógicas: escola, experiência e verdade. In: O corpo na escola. Ano XVIII boletim 04 - Abril de 2008, p. 15-19.

LIMA, E. A. de. Infância e teoria histórico-cultural: (des)encontros da teoria e prática. 2005. Tese (Doutorado em Educação) Faculdade de Filosofia e Ciências, Universidade Estadual Paulista, Marília, 2005.

MACHADO, S. da S. “Vivo ou morto?" o corpo na escola sob olhares de crianças. 2013, 207f. Dissertação (mestrado em Educação Física) - Universidade de Brasília, Distrito Federal, 2013.

MAGRIN, N. P.; CINTRA, M. M.; MOREIRA, W. W. O corpo e o professor de tempo integral. Revista Triângulo, Uberaba, v. 9, n. 2: 188-199, jul./dez. 2016.

MOREIRA, W. W. Corpo presente num olhar panorâmico. In: MOREIRA, W. W. (Org.). Corpo presente, corpo pressente. Campinas: Papirus, 1995. Cap. 1, p. 17- 36. (Coleção Corpo e Motricidade).

MOREIRA, W. W. Croniquetas: um retrato 3x4. Piracicaba: Gráfica UNIMEP, 2003.

MOREIRA, W. W. et al. Corporeidade aprendente: a complexidade do aprender viver. In: MOREIRA, W.W. (Org.). Século XXI: a era do corpo ativo. Campinas, SP: Papirus, 2006. p. 137-154 
MOREIRA, W. W. Fenômeno da corporeidade: pensado e corpo vivido. In: DANTAS, E. H. M. (Org.). Pensando o corpo e o movimento. Rio de Janeiro: Shape, 2005. p. 53-60.

MOREIRA, W. W.; SIMÕES, R. Educação física, corporeidade e motricidade: criação de hábitos para a educação e para a pesquisa. In: Educação física: cultura e sociedade. DE MARCO, A. (org.). - Campinas, SP: Papirus, 2006. p. 71-86.

MORIN, E. Os sete saberes necessário à Educação do futuro. 2 ed. Revisada. São Paulo: Cortez; DF, UNESCO, 2011.

MOTTA, F. M. N. De crianças a alunos: transformações sociais na passagem da educação infantil para o ensino fundamental. Educação e Pesquisa, São Paulo, v.37, n.1, p. 157-173, jan./abr. 2011

NISTA-PICOLLO, V. L.; MOREIRA, W.W. Corpo em movimento na Educação Infantil. São Paulo. Editora, Cortez. 2012.

NÓBREGA, T. P. da. Consciência corporal, corporeidade e educação física. In: NÓBREGA, T. P. Corporeidade e educação física: do corpo objeto ao corpo-sujeito. 2 ed. Natal: EDUFRN, 2004. p. 77-85.

NÓBREGA, T. P. da. Corporeidade e Educação Física: do corpo-objeto ao corpo-sujeito. Natal: Editora da UFRN, 2010.

NÓBREGA, T. P. Qual o lugar do corpo na Educação? Notas sobre conhecimento, processos cognitivos e currículo. Educação \& Sociedade,Campinas, vol. 26, n. 91, p. 599-615, 2005.

OLIVEIRA, M. L. (Im)pertinências da educação: o trabalho educativo em pesquisa. São Paulo: Editora UNESP; São Paulo, Cultura Acadêmica, 2010. p.193.

PÁTARO, R. F. Estratégia de projetos e complexidade na escola: possibilidades para uma educação em valores. Revista Reflexão e Ação, Santa Cruz do Sul, v.21, n.1, p.114-139, jan./jun.2013 PEDROSA, M.V.; MELLO, R. M. A. V. de. A criança de seis anos no ensino fundamental na perspectiva de mães e professoras. Revista de Educação PUC, Campinas, v.17, n. 1, p.43-54, 2012. 
PENA, A.; BOGÉA, I. C.; BORGES, L. P. Aconchegando o corpo na escola: as perspectivas/ Pensando o lugar do corpo na escola. In: Salto para o futuro - o corpo na escola. Ano XVIII, boletim 4 abril de 2008. p. 29-40

PORPINO, K. O. Dança é educação: interfaces entre corporeidade e estética. Natal/RN: EDUFRN - Editora da UFRN, 2006.

PROBST, M.; KRAEMER, C. Sentado e quieto: o lugar do corpo na escola. Atos de pesquisa em educação, Blumenau, v. 7, n. 2, p. 507-519, 2012.

RIOS, F. T. A.; MOREIRA, W. W. A importância do corpo no processo de ensino e aprendizagem. Evidência, Araxá, v. 11, n. 11, p. 49-58, 2015.

RIOS, F. T. A.; MOREIRA, W. W. O corpo na escola: qual o seu papel? Revista Triângulo, Uberaba, v. 9, n. 2, 225-237, 2016.

$S A ́$, I. R. de. O professor do primeiro ano do Ensino Fundamental e suas representações sociais sobre o movimento corporal. 2015. 286f. Tese (Doutorado em Educação) Pontifícia Universidade Católica de São Paulo, São Paulo, 2015. SANTIN, S. Educação física: uma abordagem filosófica da corporeidade. 2 ed., ljuí: Unijuí, 2003. 168 p.

SANTOS, J. C. dos. Educação Física escolar: temos o que ensinar? In: LIMA, F. R. (Org.). Os professores e suas experiências de formação, pesquisa e ensino. São Carlos: Pedro \& João Editores, 2019. 351-365 p.

SANTOS, J. C. dos.; MOREIRA, W. W. A corporeidade criança vai à escola? Educação, Santa Maria, v. 45, p. 1-27, jan/dez, 2020.

SARMENTO, M. J. As culturas da infância nas encruzilhadas da segunda modernidade. In: SARMENTO, M. J.; CERISARA, A. B. Crianças e miúdos: perspectivas sócio-pedagógicas da infância e educação. Portugal: Asa Editores, 2004. p.09-34.

SIQUEIRA, I. B. As manifestações corporais na educação infantil: um estudo sobre o corpo da criança na escola. 2014, $114 \mathrm{f}$. 
Dissertação (Mestrado em Psicologia) - Universidade de Brasília, Distrito Federal, 2014.

SKLIAR, C. As interrupções no corpo, a atenção, a ficção e a linguagem da infância. In: Vi Colóquio Internacional de Filosofia da Educação. Universidade Estadual do Rio de Janeiro (UERJ). Rio de Janeiro, Brasil, 2012.

SOBREIRA, V.; NISTA-PICCOLO, V.; MOREIRA, W. W. do corpo à corporeidade: uma possibilidade educativa. Cadernos de Pesquisa, São Luís, v. 23, n. 3, 2016.

STRAZZACAPPA, M. A educação e a fábrica de corpos: a dança na escola. Cadernos Cedes, Campinas, v.21, n. 53, p. 69-83, 2011.

TIRIBA, L. Proposta pedagógica. In: O corpo na escola. Ano XVIII boletim 04 - Abril de 2008.

TOCANTINS, G. M. de O. Apropriações de tecnologias da informação e comunicação por professores no contexto da educação do corpo na escola. 2012, 130f. n.p. Dissertação (mestrado em Educação Física) - Universidade de Brasília, Distrito Federal, 2012.

VALEIRÃO, K. Corpo + disciplina = escola? Revista Pensamento Biocêntrico, Pelotas, n.17, p. 1-32, 2012.

\section{Notas}

Este trabalho é fruto da dissertação de Mestrado em Educação Física defendida em 2019 intitulada "A corporeidade criança vai escola?"

\section{Financiamento}

Esta pesquisa contou com o apoio financeiro da Coordenação de Aperfeiçoamento de Pessoal de Nível Superior (CAPES). O se- 
O corpo em cena: reflexões para a educação escolar

José Carlos dos Santos · Wagner Wey Moreira

gundo autor é Bolsista de Produtividade de Pesquisa em Educação/ CNPq.

\section{Publisher}

Universidade Federal de Goiás. Faculdade de Educação Física e Dança. Publicação no Portal de Periódicos UFG. As ideias expressadas neste artigo são de responsabilidade de seus autores, não representando, necessariamente, a opinião dos editores ou da universidade. 